\title{
Training program for changing into a standby position (right . left) during attack and its effect on the performance level of boxing juniors
}

\section{Ahmed Kamal Abd El-Fatah Eid}

Assistant Professor in Department of Theories and Applications of Competitive and water sports, Faculty og physical education, University of Sadat city.

\section{Abstract}

The research aims to designing $A$ training program for changing into a standby position (right . left) during attack and Identifying its impact on performance level for junior boxers, the researcher chose the experimental method using the experimental design with pre and post measurements on one experimental group, the research sample was chosen intentionally form the junior of menoufia area that consists of (22) junior boxers, who were divided to the experimental research sample that consisted of (12) junior boxers, taking into account that half of them are a right boxers and the other half are left-handed boxers, to implement the proposed training program, and survey study sample, that consisted of (10) junior boxers to calculate the scientific coefficients for the tests used in the research, The training program led to development of the performance level for junior boxers with left and right positions by relying on them to changing into a standby position (right. left) during attack, which helps the boxer to verify the attack performance during the various playing positions on the ring.

\section{- Introduction and research problem:}

Boxing is one of the most prominent competitive sports that has witnessed a great development in the level of performance of its boxers and the results of its competitives in various competitions, the levels in the world championships and the latest Olympic games have advanced from a champion to another and this is due to the recent techniques of sport training, the scientific training in the field of sports training from the beginning of preparing young people until they reach high levels in various championships as a result of sound scientific planning and reliance on the results of researchers and experts specialized in various fields of science and related to sports.

To achieve winning and reach the highest levels of achievement, the coach must prepare his boxer in a way that qualifies him to benefit from his strengths, try to improve his weaknesses, train on the advantages of his opponent, and master them to overcome him, a boxer can defeat his opponent and overcome him and his way of playing through codified exercises with possible playing situations according to the opponent's playing style, which cannot be practiced in the competition and difficult to realize and deal with real when surprising, as the boxer during the match is exposed to many changing situations and surprising circumstances on the ring, and he meets many competitors such as the left-handed, the impulsive, the artist and others, and the role of the boxer comes to the right thinking and choosing the most appropriate playing style to confront the opponent, which helps him to succeed in some movement performance situations, addressing and overcoming them. (8: 34) (2: 143) (3: 91) (13:29)

The research problem becomes clear through the researcher's observation during his practice of boxing as a player and then a coach, as well as following up on many championships organized by the International Boxing Federation, it is clear that there is progress in playing styles for most boxer with advanced levels, from these styles being good at changing into standby position from right boxer to left handed boxer or the opposite during attack, where it was noticed that the boxer starts the match while performing all his offensive skills that he is good at from the right boxer position and this appears in the preparation pose in which the left foot is in 
front and the right behind as well as the left arm in front and the right behind, then the boxer surprises the opponent and turns from the right boxer position to the left-handed boxer's position, in which all his movement are performed in an inverted position, starting from the stand of his readiness, in which the right foot is in front and the left is behind, passing through his movements and ending with his offensive skills, this opposite position which the right boxers didn't use to do it is considered one of the most difficult tasks so this changing from a right boxer to a left-handed boxer during attack results in confusing the opponent during the rounds of the match, as it is difficult for the boxer to play with a right boxer and suddenly he finds a lefthanded boxer, which leads to distracting the opponent and his coach in recognizing the style of play that characterizes the boxer in terms of being a right boxer or a left-handed boxer,Therefore, the boxer and his coach cannot deal optimally with this boxer, who is able to changing into a standby position from right-handed to left-handed boxer or the opposite during attack, due to what is characterized by this boxer with his superior ability to quickly change his performance according to the changing playing positions on the ring during the rounds of the match in order to reap the largest number of points and win the match, which prompted the researcher to design a proposed training program for changing into a standby position from a right boxer to lefthanded boxer or the opposite during attack and knowing its effect on the performance level of boxing juniors.

\section{- Research Objectives:}

Designing a proposed training program for changing into a standby position (right . left) during attack to identify:

-The effect of changing into a standby position from a right boxer to left-handed boxer on the performance level of boxing juniors

-The effect of changing into a standby position from a left-handed boxer to right boxer on the performance level of boxing juniors.

- Research Hypotheses:

- There are statistically significant differences between the average of the two measurements pre and post for the experimental group in the changing into a standby position from a right boxer to left-handed boxer that effect on the performance level of boxing juniors for the average post measurement.

- There are statistically significant differences between the average of the two measurements pre and post for the experimental group in the changing into a standby position from a left-handed boxer to right boxer that effect on the performance level of boxing juniors for the average post measurement.

- Research Terminology:

- Left-handed boxer:

He is the boxer who is distinguished by a standby position in which the right foot is in front and the left foot is behind, as well as the right arm in front and the left arm behind so that the left fist is next to the chin and the elbow is adjacent to the body on the left side. (Procedural definition)

- Right boxer:

He is the boxer who is distinguished by a standby position in which the left foot is in front and the right foot is behind, as well as the left arm in front and the right arm behind so that the right fist is next to the chin and the elbow is adjacent to the body on the right side. 


\section{(Procedural definition)}

- Performance level:

It is the extent of improvement in the performance of offensive punching skills of junior boxers, which is measured through a number of skill tests to determine the level reached by these boxers. (Procedural definition)

\section{- Research Procedures:}

- Research Method:

The researcher used the experimental method for its suitability to the nature and objectives of the research, by designing a pre and post measurement for one experimental group.

\section{- Research Community:}

The research community consists of all boxers qualified to participate in the championships of the Egyptian Boxing Federation, and representatives of the Menoufia Boxing area (Youth centers . clubs).

\section{- Research Sample:}

The researcher chose the research sample in a deliberate way from the junior boxers in the Menoufia boxing area, and it consisted of (22) junior boxers who were divided to the experimental research sample that consisted of (12) junior boxers, taking into account that half of them are a right boxers and the other half are left-handed boxers, to implement the proposed training program, and survey study sample, that consisted of (10) junior boxers to calculate the scientific coefficients for the tests used in the research.

- Homogeneity Of The research Sample (Basic - survey):

The researcher made sure of the equation of the research sample (Basic - survey) of junior boxers, which consists of (22) junior boxers, in the variables (age - training age - Length weight. Pulse rate), as the Skewness is applied for all sample of the research to be sure that they are equated, which shown in Table (1):

Table (1)

Homogeneity of research sample (Basic - survey) in the variables

(Age - Training Age - Length - Weight - Pulse rate)

\begin{tabular}{cccccc}
\hline \hline The variables & Measure unit & mean & Standard deviation & Median & Skewness \\
\hline Age & month & 192.88 & 0.96 & 192.56 & 0.719 \\
\hline Training Age & month & 39.45 & 1.11 & 39.15 & 0.811 \\
\hline Length & $\mathrm{cm}$ & 165.91 & 5.26 & 165.00 & 0.519 \\
\hline Weight & $\mathrm{Kg}$ & 55.27 & 6.94 & 54.19 & 0.467 \\
\hline Pulse rate & $\mathrm{p} / \mathrm{m}$ & 73.06 & 1.73 & 72.60 & 0.798 \\
\hline \hline
\end{tabular}

Table (1) shows that Skewness among the research sample (Basic - survey) in the variables (Age - Training Age - Length - Weight - Pulse rate) were limited between $(+3,-3)$ which shows to homogeneity of the research sample in these variables.

- The methods of data collection:

The researcher used forms to record the data, which were as follows:

- A form for recording measurements of variables (age - training age - Length - weight - pulse rate) for the research sample. annex (1)

- An expert opinion survey form to determine the variables of the proposed training program for attack punches performed after changing into a standby position (right . left) for boxing juniors in the research. annex (2) 
- An expert opinion survey form to determine the most important physical and skill tests for the junior boxers and their percentage. annex (4), the researcher satisfied the physical and skill tests that exceeded the percentage (95\%).

- The form for recording the results of the skill performance level of boxing juniors. Annex (3).

- The form for recording the results of the physical and the skill tests in the research annex(7)(8).

- Scientific coefficients of the tests used:

-Validity of tests (physical - skill ):

To verify the validity of the (physical-skill) tests, the researcher conducted an survey study to calculate validity differentiation by applying the tests on sample consisted of (10) junior boxers who were chosen intentionally from research community and outside experimental research sample, and they were divided into two groups, one of them is distinguished and it consists of (5) Junior boxers with advanced positions, and the other non-distinguished and it consists of (5) Junior boxers, which shown in Table (2).

Table (2)

Indication of the differences for survey study sample (distinguished . non

Distinguished) in the physical and skill tests in the research

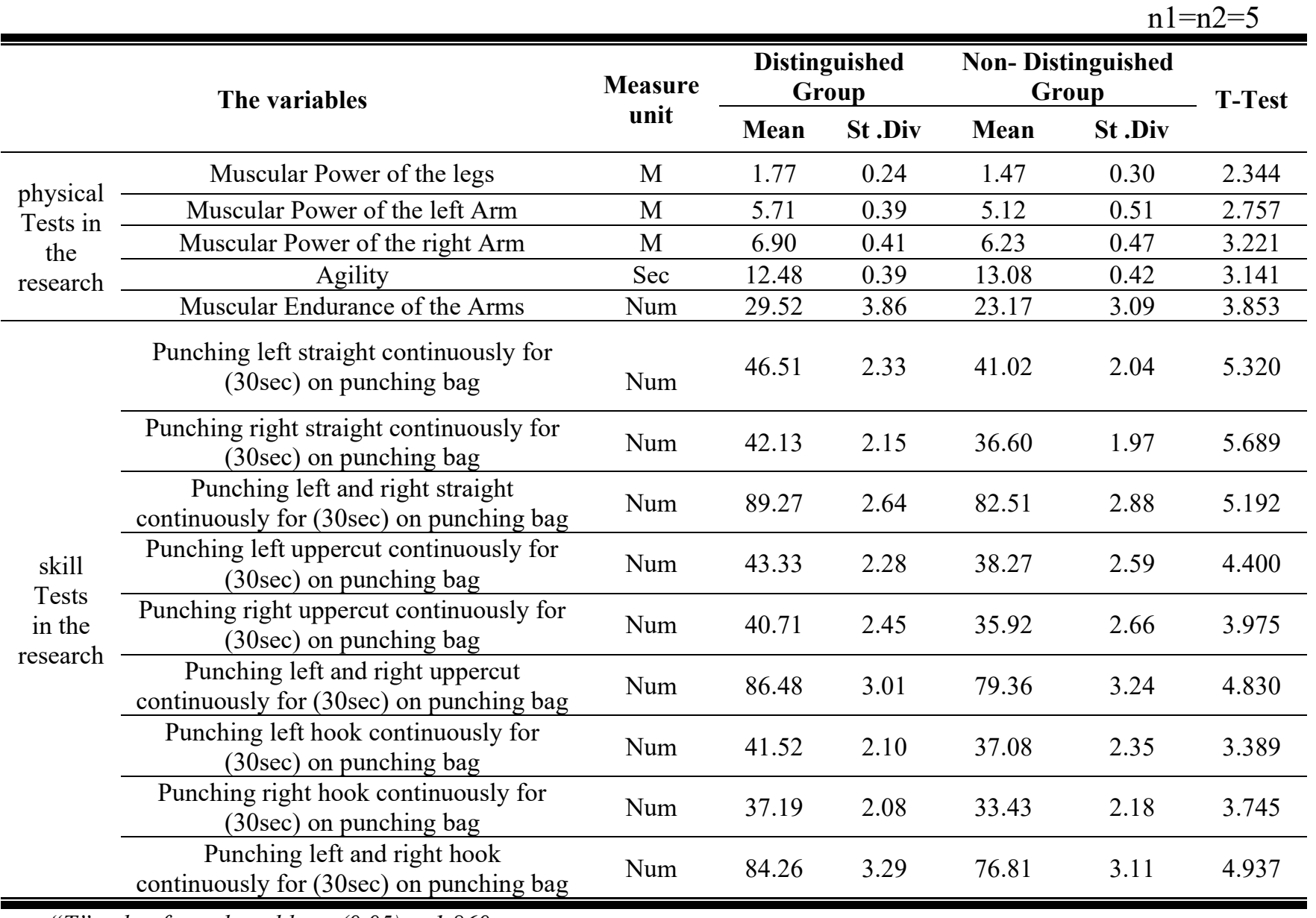

" $T$ " value from the table at $(0.05)=1.860$

Table (2) shows that there are statistically significant differences between the (distinguished - undistinguished groups) in the physical and the skill tests in the research and in favor of the distinguished group, which indicates that the physical and skill tests are able to 
distinguish between groups, and thus the tests have a high degree of validity.

- Stability of the tests (physical - skill) in the research:

To find coefficient of the stability of tests (physical - skill) in the research, the researcher used the method of applying the test and reapplying it (Test - Retest) after a week of the first application under the same conditions and instructions, to find the correlation coefficient between (first application. second application), as shown in Table (3).

Table (3)

The correlation coefficient between (first application. second application) of physical and skill tests in the research

$\mathrm{n}=(5)$

\begin{tabular}{|c|c|c|c|c|c|c|c|}
\hline & \multirow{2}{*}{ The variables } & \multirow{2}{*}{$\begin{array}{c}\text { Measure } \\
\text { unit }\end{array}$} & \multicolumn{2}{|c|}{ First application } & \multicolumn{2}{|c|}{ Second application } & \multirow{2}{*}{$\mathbf{R}$} \\
\hline & & & Mean & St .Div & Mean & St .Div & \\
\hline \multirow{5}{*}{$\begin{array}{l}\text { physical } \\
\text { Tests in } \\
\text { the } \\
\text { research }\end{array}$} & Muscular Power of the legs & M & 1.77 & 0.24 & 1.74 & 0.31 & $0.93 *$ \\
\hline & Muscular Power of the left Arm & $\mathrm{M}$ & 5.71 & 0.39 & 5.77 & 0.49 & $0.90 *$ \\
\hline & Muscular Power of the right Arm & $\mathrm{M}$ & 6.90 & 0.41 & 6.94 & 0.52 & $0.94 *$ \\
\hline & Agility & Sec & 12.48 & 0.39 & 12.41 & 0.46 & $0.91 *$ \\
\hline & Muscular Endurance of the Arms & Num & 29.52 & 3.86 & 28.73 & 3.54 & $0.92 *$ \\
\hline \multirow{9}{*}{$\begin{array}{c}\text { skill } \\
\text { Tests } \\
\text { in the } \\
\text { research }\end{array}$} & $\begin{array}{l}\text { Punching left straight continuously } \\
\text { for }(30 \mathrm{sec}) \text { on punching bag }\end{array}$ & Num & 46.51 & 2.33 & 47.42 & 2.21 & $0.92 *$ \\
\hline & $\begin{array}{l}\text { Punching right straight continuously } \\
\text { for }(30 \mathrm{sec}) \text { on punching bag }\end{array}$ & Num & 42.13 & 2.15 & 43.09 & 2.11 & $0.94 *$ \\
\hline & $\begin{array}{c}\text { Punching left and right straight } \\
\text { continuously for }(30 \mathrm{sec}) \text { on punching } \\
\text { bag }\end{array}$ & Num & 89.27 & 2.64 & 90.12 & 2.43 & $0.96 *$ \\
\hline & $\begin{array}{l}\text { Punching left uppercut continuously } \\
\text { for }(30 \mathrm{sec}) \text { on punching bag }\end{array}$ & Num & 43.33 & 2.28 & 44.05 & 2.19 & $0.93 *$ \\
\hline & $\begin{array}{l}\text { Punching right uppercut continuously } \\
\text { for }(30 \mathrm{sec}) \text { on punching bag }\end{array}$ & Num & 40.71 & 2.45 & 41.64 & 2.30 & $0.92 *$ \\
\hline & $\begin{array}{c}\text { Punching left and right uppercut } \\
\text { continuously for ( } 30 \mathrm{sec}) \text { on punching } \\
\text { bag }\end{array}$ & Num & 86.48 & 3.01 & 87.03 & 3.17 & $0.97 *$ \\
\hline & $\begin{array}{l}\text { Punching left hook continuously for } \\
\text { (30sec) on punching bag }\end{array}$ & Num & 41.52 & 2.10 & 42.04 & 2.29 & $0.92 *$ \\
\hline & $\begin{array}{l}\text { Punching right hook continuously for } \\
\text { (30sec) on punching bag }\end{array}$ & Num & 37.19 & 2.08 & 38.12 & 2.13 & $0.91 *$ \\
\hline & $\begin{array}{c}\text { Punching left and right hook } \\
\text { continuously for (30sec) on punching } \\
\text { bag }\end{array}$ & Num & 84.26 & 3.29 & 85.41 & 3.37 & $0.95^{*}$ \\
\hline
\end{tabular}

The tabulated value of " $R$ " is (0.805) at significance level (0.05)

As shown in the table (3), that the calculated value of " $R$ " is higher than the tabular value of "R", as values of the correlation coefficients between (first application. second application) in the physical and skill tests ranged between (0.90 and 0.97), which indicates Stability Tests in the research .

\section{- Homogeneity of the experimental research sample of junior boxers:}

The researcher made sure of the moderation distribution of the experimental research sample, which consists of (12) junior boxers, in(physical variables - skill variables), as shown in Table(4): 
Table (4)

Homogeneity of the experimental sample of junior boxers

In (physical variables - skill variables)

$\mathrm{n}=12$

\begin{tabular}{|c|c|c|c|c|c|c|}
\hline & The variables & $\begin{array}{c}\text { Measure } \\
\text { unit }\end{array}$ & mean & $\begin{array}{l}\text { Standard } \\
\text { deviation }\end{array}$ & Median & Skewness \\
\hline \multirow{5}{*}{$\begin{array}{l}\text { physical } \\
\text { Tests in } \\
\text { the } \\
\text { research }\end{array}$} & Muscular Power of the legs & M & 1.78 & 0.3924 & 1.75 & 0.375 \\
\hline & Muscular Power of the left Arm & $\mathrm{M}$ & 5.73 & 0.37 & 5.70 & 0.243 \\
\hline & Muscular Power of the right Arm & $\mathrm{M}$ & 6.88 & 0.43 & 6.85 & 0.209 \\
\hline & Agility & $\mathrm{Sec}$ & 12.45 & 0.35 & 12.40 & 0.429 \\
\hline & Muscular Endurance of the Arms & Num & 29.69 & 2.28 & 29.60 & 0.118 \\
\hline \multirow{9}{*}{$\begin{array}{c}\text { skill } \\
\text { Tests } \\
\text { in the } \\
\text { research }\end{array}$} & $\begin{array}{l}\text { Punching left straight continuously for } \\
\text { (30sec) on punching bag }\end{array}$ & Num & 47.85 & 1.48 & 47.65 & 0.405 \\
\hline & $\begin{array}{l}\text { Punching right straight continuously for } \\
(30 \mathrm{sec}) \text { on punching bag }\end{array}$ & Num & 43.09 & 1.53 & 42.70 & 0.765 \\
\hline & $\begin{array}{l}\text { Punching left and right straight continuously } \\
\text { for }(30 \mathrm{sec}) \text { on punching bag }\end{array}$ & Num & 90.41 & 1.79 & 90.00 & 0.687 \\
\hline & $\begin{array}{l}\text { Punching left uppercut continuously for } \\
(30 \mathrm{sec}) \text { on punching bag }\end{array}$ & Num & 44.57 & 2.08 & 44.25 & 0.462 \\
\hline & $\begin{array}{l}\text { Punching right uppercut continuously for } \\
(30 \mathrm{sec}) \text { on punching bag }\end{array}$ & Num & 41.89 & 1.39 & 41.55 & 0.734 \\
\hline & $\begin{array}{l}\text { Punching left and right uppercut continuously } \\
\text { for }(30 \mathrm{sec}) \text { on punching bag }\end{array}$ & Num & 87.60 & 1.62 & 87.30 & 0.555 \\
\hline & $\begin{array}{l}\text { Punching left hook continuously for (30sec) } \\
\text { on punching bag }\end{array}$ & Num & 42.71 & 1.93 & 42.60 & 0.710 \\
\hline & $\begin{array}{l}\text { Punching right hook continuously for (30sec) } \\
\text { on punching bag }\end{array}$ & Num & 38.35 & 1.86 & 38.10 & 0.402 \\
\hline & $\begin{array}{l}\text { Punching left and right hook continuously for } \\
(30 \mathrm{sec}) \text { on punching bag }\end{array}$ & Num & 85.66 & 2.12 & 85.05 & 0.863 \\
\hline
\end{tabular}

As shown in the table (4) that the values of the Skewness coefficients among the experimental sample in the physical and skill variables were limited between $(0.118,0.863)$, that is they were limited to $( \pm 3)$, which shows the homogeneity of the experimental sample of the junior boxers in those variables in the research.

- The Foundations of putting the proposed training program in the research:

. The program training is compatible with the objectives set.

. Taking into account the principles of training when putting the training program .

. Training program flexibility and its ability to be adjustable in any time .

. The suitability of the training program to the age of the sample.

. Regular practice of the exercises set in the program until it has the desired benefit.

- Determinants of the training program in the research:

- The training program applying period:

The time plan for applying the proposed training program consists of (12) weeks, with (36) training units, each week consists of (3) training units, and the time of the training unit in the program (90 minutes). annex (5)

- Determination of the attack punches performed after changing to a left- or right- handed boxer position:

The attack punches performed after changing to the left-handed or right-handed boxer position were determined for the Sunni stage in question by presenting the skills to the experts 
annex (9) and placing them in the proposed training program, namely:

. From the right boxer's position, changing to the left-handed and punching right straight with the front arm, and punching left straight with the back arm.

. From the left-handed boxer's position, changing to the right and punching left straight with the front arm, and punching right straight with the back arm.

. From the right boxer's position, changing to the left-handed and punching right uppercut with the front arm, and punching left uppercut with the back arm.

. From the left-handed boxer's position, changing to the right and punching left uppercut with the front arm, and punching right uppercut with the back arm.

. From the right boxer's position, changing to the left-handed and punching right hook with the front arm, and punching left hook with the back arm.

. From the left-handed boxer's position, changing to the right and punching left hook with the front arm, and punching right hook with the back arm.

- Training methods used in the training program:

The training method which used in the training program was determined, and the experts agreed to use training method (high intensity interval - low intensity interval).

- The load intensity used in the proposed training program was determined, as the load intensity of the experimental group in the selected skills ranged between $(51 \%$ : $95 \%)$, and with a pulse rate between $(140: 197) \mathrm{Pulse} / \mathrm{min}$, and the training loads were rationed using a rate of Pulse through this equation:

-Training Target pulse Rate $=$

Resting pulse rate $+[$ Training ratio $\times$ (Maximum pulse rate - Resting pulse rate) /100] Where:

- Maximum pulse rate $=220-$ age $=\ldots$. Pulse $/$ min

- Reserves maximum rate of the pulse $=$ Maximum pulse rate - pulse rate at rest $=\ldots$ Pulse $/ \mathrm{min}$

\section{- Rationing of training loads inside the proposed program:}

- Average age of junior boxers' sample in the research (16 years).

- Average pulse rate at rest of junior boxers sample (73) pulse/min.

- $\quad$ Maximum pulse rate $=220$ - average age

Maximum pulse rate for junior boxers' sample $=220-16=204 \mathrm{pulse} / \mathrm{min}$

- $\quad$ Reserves of pulse $=$ Maximum pulse rate - pulse rate at rest

Reserves of pulse for junior boxers' sample $=204-73=131 \mathrm{pulse} / \mathrm{min}$.

- Rationing of training loads by using pulse rate:

- (Average load): percentage (50:74\%) and Pulse rate (139:170) pulse/min.

- (High load): percentage (75:89\%) and Pulse rate (171:190) pulse/min.

- (Maximum load): percentage (90:100 \%) and Pulse rate(191:204) pulse/min.

- The pre - measurement:

The researcher conducted a pre-measurement for the experimental research sample of junior boxers on Thursday, 3/6/2021, to identify the level of skill performance of junior boxers, through the data registration form prepared for this.

- Applying the proposed training program:

The researcher applied the training program on junior boxers' sample, for a period of (12) weeks, with a total of (36) training units, from Sunday 6/6/2021 until Thursday 26/8/2021.

- The Post - measurement:

The researcher conducted a post-measurement for the experimental research sample of junior boxers on Friday, 27/8/2021, to identify the level of skill performance of junior boxers, through 
the data registration form prepared for this.

- Statistical processing in the research:

The researcher used the statistical processes to process the data:

Arithmetic mean - standard deviation - Median - T. test Correlation coefficient - Skewness.

- Presentation and discussion of results of the first hypothesis:

\section{Table (5)}

Indication of the differences between (Pre measurement - Post measurement)

for (right boxer's position and Changing to a left-handed

boxer's position) in the level of skill performance

\begin{tabular}{|c|c|c|c|c|c|}
\hline \multirow{3}{*}{ The Research variables } & \multicolumn{5}{|c|}{$\mathrm{N}=(6)$} \\
\hline & \multicolumn{2}{|c|}{ Pre - measurement } & \multicolumn{2}{|c|}{ Post - measurement } & \multirow{2}{*}{$\begin{array}{c}\text { T- } \\
\text { Test }\end{array}$} \\
\hline & Mean & St .Div & Mean & St .Div & \\
\hline $\begin{array}{l}\text { From the right boxer's position, Punching left straight } \\
\text { continuously for }(30 \mathrm{sec}) \text { with the front arm. }\end{array}$ & 48.12 & 1.86 & 53.02 & 1.90 & 4.121 \\
\hline $\begin{array}{l}\text { Changing to a left-handed boxer's position, and Punching } \\
\text { right straight continuously for }(30 \mathrm{sec}) \text { with the front arm. }\end{array}$ & 40.65 & 2.20 & 45.81 & 2.11 & 3.786 \\
\hline $\begin{array}{l}\text { From the right boxer's position, Punching right straight } \\
\text { continuously for ( } 30 \mathrm{sec} \text { ) with the back arm. }\end{array}$ & 42.73 & 1.53 & 46.31 & 1.80 & 3.559 \\
\hline $\begin{array}{l}\text { Changing to a left-handed boxer's position, and Punching } \\
\text { left straight continuously for }(30 \mathrm{sec}) \text { with the back arm. }\end{array}$ & 33.28 & 1.47 & 38.10 & 1.69 & 4.810 \\
\hline $\begin{array}{l}\text { From the right boxer's position, Punching left and right } \\
\text { straight continuously for }(30 \mathrm{sec}) \text {. }\end{array}$ & 90.81 & 2.61 & 97.94 & 2.33 & 4.556 \\
\hline $\begin{array}{l}\text { Changing to a left-handed boxer's position, Punching left } \\
\text { and right straight continuously for }(30 \mathrm{sec}) \text {. }\end{array}$ & 81.43 & 2.93 & 87.62 & 2.71 & 3.468 \\
\hline $\begin{array}{l}\text { From the right boxer's position, Punching left uppercut } \\
\text { continuously for }(30 \mathrm{sec}) \text { with the front arm. }\end{array}$ & 45.39 & 1.94 & 49.86 & 1.85 & 3.728 \\
\hline $\begin{array}{l}\text { Changing to a left-handed boxer's position, and Punching } \\
\text { right uppercut continuously for }(30 \mathrm{sec}) \text { with the front arm. }\end{array}$ & 35.02 & 2.16 & 39.72 & 2.03 & 3.544 \\
\hline $\begin{array}{l}\text { From the right boxer's position, Punching right uppercut } \\
\text { continuously for }(30 \mathrm{sec}) \text { with the back arm. }\end{array}$ & 42.03 & 1.75 & 47.39 & 1.69 & 5.423 \\
\hline $\begin{array}{l}\text { Changing to a left-handed boxer's position, and Punching } \\
\text { left uppercut continuously for }(30 \mathrm{sec}) \text { with the back arm. }\end{array}$ & 33.41 & 1.89 & 39.81 & 1.94 & 5.285 \\
\hline $\begin{array}{l}\text { From the right boxer's position, Punching left uppercut and } \\
\text { right continuously for ( } 30 \mathrm{sec}) \text {. }\end{array}$ & 88.63 & 2.17 & 95.70 & 2.31 & 4.989 \\
\hline $\begin{array}{l}\text { Changing to a left-handed boxer's position, Punching left } \\
\text { and right uppercut continuously for }(30 \mathrm{sec}) \text {. }\end{array}$ & 77.15 & 2.34 & 85.03 & 2.26 & 5.420 \\
\hline $\begin{array}{l}\text { From the right boxer's position, Punching left hook } \\
\text { continuously for ( } 30 \mathrm{sec}) \text { with the front arm. }\end{array}$ & 42.13 & 2.05 & 47.21 & 2.18 & 3.797 \\
\hline $\begin{array}{l}\text { Changing to a left-handed boxer's position, and Punching } \\
\text { right hook continuously for }(30 \mathrm{sec}) \text { with the front arm. }\end{array}$ & 31.06 & 1.95 & 35.92 & 1.70 & 4.200 \\
\hline $\begin{array}{l}\text { From the right boxer's position, Punching right hook } \\
\text { continuously for (30sec) with the back arm. }\end{array}$ & 37.07 & 1.81 & 43.65 & 1.92 & 5.576 \\
\hline $\begin{array}{l}\text { Changing to a left-handed boxer's position, and Punching } \\
\text { left hook continuously for }(30 \mathrm{sec}) \text { with the back arm. }\end{array}$ & 28.51 & 1.72 & 34.70 & 1.54 & 5.998 \\
\hline $\begin{array}{l}\text { From the right boxer's position, Punching left and right hook } \\
\text { continuously for }(30 \mathrm{sec}) \text {. }\end{array}$ & 84.29 & 2.60 & 91.41 & 2.43 & 4.472 \\
\hline $\begin{array}{l}\text { Changing to a left-handed boxer's position, Punching left } \\
\text { and right hook continuously for ( } 30 \mathrm{sec}) \text {. }\end{array}$ & 73.12 & 2.54 & 80.57 & 2.40 & 4.766 \\
\hline
\end{tabular}

The tabulated value of " $T$ " (2.015) at significance level (0.05)

Table (5) shows that there are statistically significant differences at the level (0.05) between the two measurements (pre - post) in the tests of skill variables for (right boxer's position and 
Changing to a left-handed boxer's) in favor of the post measurement, where the calculated (T) value is higher than tabulated value of $(\mathrm{T})$ at a significant level (0.05), and this is evident through the following:

The calculated $(\mathrm{T})$ value was $(4,121)$ for punching left straight with the front arm from the position of the right boxer, and after changing into a left-handed boxer and punching right straight with the front arm, the calculated (T)value was $(3,786)$.

The calculated $(\mathrm{T})$ value was $(3,559)$ for punching right straight with the back arm from the right boxer's position, and after changing into a left-handed boxer and Punching left straight with the back arm, the calculated $(\mathrm{T})$ value was $(4,810)$.

The calculated $(\mathrm{T})$ value was $(4,556)$ for punching left and right straight from the right boxer position, and after changing into a left-handed boxer and punching left and right straight, the calculated $(\mathrm{T})$ value was $(3,468)$.

The calculated (T)value was $(3,728)$ for punching left uppercut with the front arm from the position of the right boxer, and after changing into a left-handed boxer and punching right uppercut with the front arm, calculated (T)value was $(3,544)$.

The calculated $(\mathrm{T})$ value was $(5,423)$ for punching right uppercut continuously for $(30 \mathrm{sec})$ with the back arm from the position of the right boxer and after changing into a left-handed boxer and punching left uppercut with the back arm, calculated $(\mathrm{T})$ value was $(5,285)$.

The calculated $(\mathrm{T})$ value was also $(4,989)$ for punching left uppercut and right from the right boxer position, and after changing into a left-handed boxer and punching left and right uppercut, the calculated $(\mathrm{T})$ value reached $(5,420)$.

The calculated $(\mathrm{T})$ value was $(3,797)$ for punching left hook with the front arm from the right boxer position, and after changing into a left-handed boxer and punching right hook with the front arm, the calculated (T) value was $(4,200)$.

The calculated $(\mathrm{T})$ value was $(5,576)$ for punching right hook with the back arm from the right boxer position, and after changing into a left-handed boxer and punching left hook with the back arm, the calculated $(\mathrm{T})$ value was $(5,998)$.

The calculated $(\mathrm{T})$ value was $(4,472)$ for punching left and right hook from the right boxer position, and after changing into a left-handed boxer and punching left and right hook, the calculated $(\mathrm{T})$ value was $(4,766)$, The researcher attributed this to the fact that the proposed training program contains many exercises to changing from the right boxer position to the lefthanded and perform various attack punches, which were applied to the junior boxers, the experimental research sample by the rationed method according to a specific time schedule, which contributed to gaining these junior boxers sufficient self-confidence and gave them the ability to change from the right-handed boxer to left-handed during the attack, and thus positively affected the development of their performance level for the attack skills of the righthanded boxer, as well as when changing them to the left-handed, as the boxer's changing from right-handed to left-handed distracts the opponent and then carrying out the attack skills Efficiently and get the most points during the game rounds.

This is consistent with the results of some studies and references, which indicated that the attack performance during the competition is multi-objective and multi-purpose, so the boxer's movement performance must be characterized by speed with the use of camouflaging movements to carry out the direct attack from the appropriate distances while choosing the right timing and maintaining his balance during the attack, where the success of the attack in the sport of boxing is based on the moment of the arrival of one or more offensive punches to the competitor and achieving its goal according to the type of distance and the advantages of 
approaching the competitor according to the requirements of the situation and the capabilities of the boxer in terms of preparing various deceptive movements and choosing a suitable place on the ring as a starting point for the carrying out the attack on the opponent.

$(3: 33)(9: 12)(7: 26)(5: 9)(10)$

Some references also indicate that the boxer can defeat his unbeaten opponent and overcome him and his way of playing through a rationed training process with possible tactical playing situations similar to the style of the competitor, which cannot be practiced in competition and difficult to realize and really deal with it when surprising, which helps him to succeed in some movement performance situations and to confront and overcome them. (8: 34) (3:143) (13:29)

\section{- Presentation and discussion of results of the second hypothesis:}

Table (6)

Indication of the differences between (Pre measurement - Post measurement)

for (left-handed boxer's position and Changing to a right boxer's position)

in the level of skill performance

\begin{tabular}{|c|c|c|c|c|c|}
\hline \multirow{2}{*}{ The Research variables } & \multicolumn{2}{|c|}{ Pre - measurement } & \multicolumn{2}{|c|}{ Post - measurement } & \multirow{2}{*}{$\begin{array}{c}\text { T- } \\
\text { Test }\end{array}$} \\
\hline & Mean & St .Div & Mean & St .Div & \\
\hline $\begin{array}{l}\text { From the right boxer's position, Punching left straight } \\
\text { continuously for }(30 \mathrm{sec}) \text { with the front arm. }\end{array}$ & 44.36 & 1.78 & 47.59 & 1.48 & 3.122 \\
\hline $\begin{array}{l}\text { Changing to a left-handed boxer's position, and Punching } \\
\text { right straight continuously for }(30 \mathrm{sec}) \text { with the front arm. }\end{array}$ & 34.81 & 1.95 & 38.82 & 1.72 & 3.448 \\
\hline $\begin{array}{l}\text { From the right boxer's position, Punching right straight } \\
\text { continuously for }(30 \mathrm{sec}) \text { with the back arm. }\end{array}$ & 47.13 & 1.36 & 51.04 & 1.53 & 4.273 \\
\hline $\begin{array}{l}\text { Changing to a left-handed boxer's position, and Punching } \\
\text { left straight continuously for }(30 \mathrm{sec}) \text { with the back arm. }\end{array}$ & 37.50 & 1.28 & 40.96 & 1.38 & 4.019 \\
\hline $\begin{array}{l}\text { From the right boxer's position, Punching left and right } \\
\text { straight continuously for }(30 \mathrm{sec}) \text {. }\end{array}$ & 91.93 & 2.85 & 98.14 & 2.46 & 3.688 \\
\hline $\begin{array}{l}\text { Changing to a left-handed boxer's position, Punching left } \\
\text { and right straight continuously for }(30 \mathrm{sec}) \text {. }\end{array}$ & 82.04 & 2.72 & 89.27 & 2.32 & 4.522 \\
\hline $\begin{array}{c}\text { From the right boxer's position, Punching left uppercut } \\
\text { continuously for }(30 \mathrm{sec}) \text { with the front arm. }\end{array}$ & 41.22 & 2.23 & 46.10 & 2.07 & 3.586 \\
\hline $\begin{array}{l}\text { Changing to a left-handed boxer's position, and Punching } \\
\text { right uppercut continuously for }(30 \mathrm{sec}) \text { with the front arm. }\end{array}$ & 32.41 & 2.55 & 37.22 & 2.14 & 3.230 \\
\hline $\begin{array}{l}\text { From the right boxer's position, Punching right uppercut } \\
\text { continuously for }(30 \mathrm{sec}) \text { with the back arm. }\end{array}$ & 46.90 & 1.83 & 50.71 & 1.93 & 3.204 \\
\hline $\begin{array}{l}\text { Changing to a left-handed boxer's position, and Punching } \\
\text { left uppercut continuously for }(30 \mathrm{sec}) \text { with the back arm. }\end{array}$ & 35.22 & 1.62 & 39.94 & 1.41 & 4.917 \\
\hline $\begin{array}{l}\text { From the right boxer's position, Punching left uppercut and } \\
\text { right continuously for }(30 \mathrm{sec}) .\end{array}$ & 87.39 & 2.31 & 95.80 & 2.15 & 5.960 \\
\hline $\begin{array}{l}\text { Changing to a left-handed boxer's position, Punching left } \\
\text { and right uppercut continuously for }(30 \mathrm{sec}) \text {. }\end{array}$ & 76.51 & 2.19 & 84.35 & 1.94 & 5.994 \\
\hline $\begin{array}{l}\text { From the right boxer's position, Punching left hook } \\
\text { continuously for }(30 \mathrm{sec}) \text { with the front arm. }\end{array}$ & 39.11 & 1.82 & 43.12 & 1.63 & 3.669 \\
\hline $\begin{array}{l}\text { Changing to a left-handed boxer's position, and Punching } \\
\text { right hook continuously for }(30 \mathrm{sec}) \text { with the front arm. }\end{array}$ & 29.73 & 1.75 & 34.02 & 1.89 & 3.724 \\
\hline $\begin{array}{l}\text { From the right boxer's position, Punching right hook } \\
\text { continuously for }(30 \mathrm{sec}) \text { with the back arm. }\end{array}$ & 40.26 & 2.10 & 46.33 & 2.26 & 4.399 \\
\hline $\begin{array}{l}\text { Changing to a left-handed boxer's position, and Punching } \\
\text { left hook continuously for }(30 \mathrm{sec}) \text { with the back arm. }\end{array}$ & 31.95 & 1.84 & 36.72 & 1.70 & 4.259 \\
\hline
\end{tabular}




\begin{tabular}{ccccc}
\hline \hline $\begin{array}{c}\text { From the right boxer's position, Punching left and right hook } \\
\text { continuously for (30sec). }\end{array}$ & 85.10 & 2.72 & 93.42 & 2.58 \\
\hline $\begin{array}{c}\text { Changing to a left-handed boxer's position, Punching left } \\
\text { and right hook continuously for (30sec). }\end{array}$ & 74.36 & 2.19 & 81.56 & 2.10 \\
\hline \hline
\end{tabular}

The tabulated value of " $T$ " (2.015) at significance level (0.05

Table (6) shows that there are statistically significant differences at the level $(0.05)$ between the two measurements (pre - post) in the tests of skill variables for (left-handed boxer's position and Changing to a right boxer's) in favor of the post measurement, where the calculated (T) value is higher than tabulated value of " $T$ " at a significant level $(0.05)$, and this is evident through the following:

The calculated $(\mathrm{T})$ value was $(3,121)$ for punching left straight with the back arm from the lefthanded boxer's position, and after changing into a right-handed boxer and punching right straight with the back arm, calculated $(\mathrm{T})$ value was $(3,448)$.

The calculated (T)value was(4,273)for punching right straight with the front arm from the lefthanded boxer's position, and after changing into a right-handed boxer and punching left straight with the front arm, calculated (T) value was $(4,019)$.

The calculated $(\mathrm{T})$ value was $(3,688)$ for punching left and right straight from the left-handed boxer, and after changing into a right-handed boxer and punching left and right straight, the calculated $(\mathrm{T})$ value was $(4,522)$.

The calculated (T)value was(3,586)for punching left uppercut with the back arm from the lefthanded boxer's position, and after changing into a right-handed boxer and punching right uppercut with the back arm, calculated (T)value was $(3,230)$.

The calculated $(\mathrm{T})$ value was $(3,204)$ for punching right uppercut with the front arm from the left-handed boxer's position, and after changing into a right-handed boxer and punching left uppercut with front arm, calculated $(\mathrm{T})$ value was $(4,917)$.

The calculated $(\mathrm{T})$ value was also $(5,960)$ for punching left and right uppercut from the lefthanded boxer's position, and after changing into a right-handed boxer and punching left and right uppercut, the calculated (T) value reached $(5,994)$.

The calculated $(\mathrm{T})$ value was $(3,669)$ for Punching left hook with the back arm from the lefthanded boxer position, and after changing into a right-handed boxer and punching right hook with the back arm, the calculated (T) value was $(3,724)$.

The calculated $(\mathrm{T})$ value was $(4,399)$ for punching right hook with the front arm from the lefthanded boxer's position, and after changing into a right-handed boxer and punching left hook with the front arm, the calculated $(\mathrm{T})$ value was $(4,259)$.

The calculated $(\mathrm{T})$ value was also $(5,152)$ for punching left and right hook from the lefthanded boxer's position, and after changing into a right boxer and punching left and right hook, the calculated $(\mathrm{T})$ value was $(5,313)$, The researcher attributes this to the fact that the proposed training program contains many exercises for changing from the left-handed boxer into the lefthanded boxer and performing various attack punches, which were applied to the junior boxers, the experimental research sample in the scientific method codified according to a specific time schedule, which contributed to these junior boxers gaining sufficient self confidence, and it gave them the ability to change from the left-handed boxer position into the right-handed during the attack, and thus positively affected the development of their performance level of attack skills from the left-handed boxer position, as well as when changing into right-handed, as the boxer's changing from left-handed to right-handed distracts the opponent and then implements attack skills efficiently and obtains the largest number of points. 
This is consistent with the results of some studies and references, which indicated that the boxer must use appropriate methods to carry out the attack efficiently and effectively during the match. Moving with the feet in all directions so that the boxer can fire delves attack punches that represent a serious danger to the opponent. The boxer bears full responsibility for the efficiency of his performance throughout the match by maintaining his superiority and controlling his opponent and overcoming him with appropriate attack methods without decreasing the level, by making the maximum effort during the competition. Self-motivated, keeping in mind the attempts to win. (12:12) (6:14) (9:17) (11)

Some references also point to the need to prepare the boxer in a way that qualifies him to take advantage of his strengths and try to improve his performance and training on the advantages of his opponent and mastery to overcome him, and in the event that the competitor is unknown, the coach must direct his player to use feints to explore the weaknesses of the competitor while following the factors of caution The role of the boxer comes to the proper thinking and the selection and organization of his tactical methods that are most appropriate to confront the opponent. $(3: 91)(8: 34)(1: 12)$

\section{- Conclusions:}

Through the results that have been reached by the researcher, the conclusions came as follows:

- There are statistically significant differences between the averages of the two measurements (pre - post) in the performance of the attack skills of the junior right-handed boxers, as well as when changing into left-handed and in favor of the average post-measurement.

- There are statistically significant differences between the averages of the two measurements (pre - post) in the performance of the attack skills of the junior left-handed boxers, as well as when changing into right-handed and in favor of the average post-measurement.

- The training program led to development of the performance level for junior boxers with left and right positions by relying on them to change from the right position into the left position during the attack, as well as changing from the left position into the right position during the attack, which helps the boxer to verify the attack performance during the various playing positions on the ring.

- Recommendations:

- It's important for those in charge of boxing activity to pay attention to the style of play that depends on the changing in the standby position (right-handed - left-handed) during the attack and training the junior boxers on it in order to develop their performance to match the requirements of the competition and the competitor, and achieve them to reach the higher levels.

- The necessity of developing rationed and scientifically based training programs for the other age stages to change into the standby position (right-handed - left-handed) during the attack.

- Holding seminars to draw the attention of the coaches to the importance of changing into the standby position (right-handed - left-handed) during the attack and its positive role in leading the course of the match through verifying in attack performance according to the changing playing positions on the ring.

\section{References}

1- Abd -Al Rahman Abdel Azim Seif (2010): Biochemical changes for continuous and periodic training of boxers, Alexandria Knowledge Facility.

2-Abd -Al Rahman Abdel Azim Seif (2011): Sports Training for Boxers, Dar Al-Wafaa for Donia Printing and Publishing, First Printer, Alexandria. 
3-Abd -El Fattah Fathi Khader (1996): The reference in boxing, Monchaat Al-Maaref, Alexandria.

4-Abu -Elala Ahmed Abdel-Fattah, Ahmed Nasr El-Din (2003): Physiology of physical fitness, Dar of the Arab Thought, Cairo.

5-Ahmed Kamal Eid (2016): Effect of training program for attack accompanied by foot work after feint on development of performance level for boxing juniors, published research, Scientific Journal of Sports Science and Arts, Faculty of Physical Education for girls, Helwan University.

6-Ahmed Saied Khader (2012): The rates of using attack punching skills (single - double punching groups) and their defenses for boxers participating in the Olympic Games in London (2012), published research, Scientific Journal of Physical Education and Sports, Faculty of Physical Education for Boys, Helwan University.

7-Ahmed Saied Khader, Ahmed Kamal Eid (2014): The effect of using ring art methods on the development of some physical and tactical variables for young boxers, published research, The Scientific Journal of Physical Education and Sports Sciences, Faculty of Physical Education for Boys, Helwan University.

8-Ismail Hamed Othman, Mohamed Abdel Aziz Ghoneim, Diaa Mohamed Al-Azab, Atef Maghawry Shaalan (2005): Boxing - Education, Training and Management, 3rd Edition, Cairo.

9-Mohamed Abdel Aziz Ghoneim (1995): Analytical study of the effectiveness of attack and defense plans for Arab boxers, published research, Scientific Journal of Physical Education and Sports, Faculty of Physical Education, Tanta University.

10- Tomasz (2001): technique of attack of the best amateur boxers of the world and Europe.

11- Verlag (1996): methods of training -boxing, teaches the c.v. mostly company saint Louis.

12- Yahya Ismail Al-Hawi (1997): Boxing (theoretical foundations - practical applications), Al-Aziz Computer Library, Zagazig.

13- Yahya Ismail Al-Hawi (2004): Sports talent and movement creativity, the Arab Center for Publishing, Zagazig. 